\title{
Impact of hemochromatosis screening in patients with indeterminate results: The hemochromatosis and iron overload screening study
}

Roger T. Anderson, $P h D^{1}$, Lari Wenzel, PhD ${ }^{2}$, Ann P. Walker, MA, CGC $C^{3}$, Andrea Ruggiero, $M S^{1}$, Ronald T. Acton, PhD ${ }^{4}$, Mark A. Hall, $J D^{1}$, Diane C. Tucker, $P h D^{5}$, Elizabeth Thomson, MS, $R N^{6}$, Barbara Harrison, $\mathrm{MS}^{7}$, Edmund Howe III, $\mathrm{MD}$, $\mathrm{JD}^{7}$, Joan Holup, $\mathrm{MA}^{8}$, Catherine Leiendecker-Foster, $\mathrm{MS}^{9}$, Tara Power, $P h D^{10}$, and Paul Adams, $M D^{11}$

\begin{abstract}
Purpose: Assess the quality of life impact of receiving indeterminate test results for hemochromatosis, a disorder involving HFE genetic mutations and/or elevated serum transferrin saturation and ferritin. Methods: The study sample was from the Hemochromatosis and Iron Overload Screening Study, a large observational study of hemochromatosis among primary care patients in the US and Canada using HFE genotype and serum transferrin saturation and ferritin screening. Study subjects included 2,304 patients found with hemochromatosis risk of uncertain clinical significance. Assessed was SF-36 general health and emotional well-being before screening and six weeks after participants received their test results. Health worries were assessed after screening. Results: Of the study subjects, 1,268 participants (51.5\%) completed both assessments. Compared to normal controls, those with HFE mutations or elevated serum transferrin saturation and ferritin levels of uncertain significance were more likely to report diminished general health and mental well-being, and more health worries. These effects were associated with participants' belief of having tested positive for hemochromatosis or iron overload. Conclusion: Notification of indeterminate results from screening may be associated with mild negative effects on well-being, and might be a potential participant risk in screening programs for disorders with uncertain genotype-phenotype. Genet Med 2006:8(11):681-687.
\end{abstract}

Key Words: Hemochromatosis, screening, acceptance, ethics, primary care, HEIRS

Routine screening for genetic-based disease is increasingly possible for many diseases and disorders, offering a means to detect latent risk for disease long before clinical expression and allowing primary prevention. ${ }^{1,2}$ Hereditary hemochromatosis $(\mathrm{HH})$ is an example in which this opportunity is offerred. ${ }^{3-5}$ $\mathrm{HH}$ is a blood disorder associated with mutations in the HFE gene ${ }^{6,7}$ that occurs in 1 in 227 Caucasians. ${ }^{8}$ It is a serious health concern but is easily detected through genotypic testing, or phenotypic testing. The risk of biochemical iron overload can be predicted by genotype and gender. ${ }^{9}$ Male C282 years ho-

\footnotetext{
From the ${ }^{I}$ Department of Public Health Sciences, Wake Forest University School of Medicine, Winston-Salem, NC; ${ }^{2}$ Center for Health Policy Research, Department of Medicine, University of California, Irvine, CA; ${ }^{3}$ Department of Pediatrics, University of California, Irvine Medical Center, Irvine, CA; ${ }^{4}$ Departments of Microbiology, and Epidemiology and International Health, University of Alabama at Birmingham, Division of Human Genetics, ${ }^{5}$ Department of Psychology, University of Alabama at Birmingham; ${ }^{6}$ National Human Genome Research Institute, Bethesda, $M D ;{ }^{7}$ Department of Psychiatry, Uniformed Services University of Health, Bethesda, $M D ;{ }^{8}$ Kaiser Permanente Center for Health Research, Portland, OR; ${ }^{9}$ Department of Laboratory Medicine and Pathology, University of Minnesota; ${ }^{10}$ Department of Psychology, University of Western Ontario, London, Ontario, Canada; and ${ }^{11}$ Department of Medicine, London Health Sciences Center, London Ontario, Canada.

Roger T. Anderson, PhD, Department of Public Health Sciences, Wake Forest University School of Medicine, Medical Center Blvd, Winston-Salem, NC 27157.

Submitted for publication. March 22, 2006.

Accepted for publication August 29, 2006.
}

DOI: 10.1097/01.gim.0000245631.07117.ac mozygotes have the highest risk of iron overload (88\%). ${ }^{10}$ Survival is dependent on the prevalence of cirrhosis which is low in population screening studies (1-4\% $)^{11,12}$ but as high as $15 \%$ in referred patients. ${ }^{13,14}$ Patients with cirrhosis have a 5.5-fold relative risk of death compared to the noncirrhotic hemochromatosis patients. ${ }^{15,16} \mathrm{HH}$ can cause other complications such as primary liver cancer, diabetes mellitus or other endocrinopathy, arthropathy, cardiomyopathy, and reduced longevity, ${ }^{17,18}$ but timely treatment can prevent many of these complications. ${ }^{19}$ Routine screening for genetic disorders is controversial. For $\mathrm{HH}$, as well as for other diseases, negative effects from screening have been discussed $^{20-22}$ such as stigmatization, ${ }^{23,24}$ the anxiety of being found with genetic risk for disease, ${ }^{25-28}$ and knowing that one needs long-term treatment. These risks however must be weighed against the potential benefits of disease prevention ${ }^{29}$ and might be deemed acceptable, especially if steps are taken to reduce distress through routine genetic counseling.

However, the potential for a favorable risk/benefit ratio from screening appears to not apply to a potentially large proportion of screened individuals found to have "indeterminate results." For genotypes or phenotypes with an uncertain (yet believed nontrivial) relationship to disease, it would be difficult to genuinely reassure patients or to provide specific recommendations for surveillance. Moreover, it is uncertain how patients may react to notification of indeterminate test results and therefore how to weigh 
this potential risk against the potential future benefit of knowing one has a genetic mutation that has received some research interest. For some, the knowledge of having uncertain risk with no recommended treatment for prevention could be distressing or even misunderstood, especially if risk counseling is not offered. The option of simply not notifying patients of results for indeterminate genotype risk is problematic as they may have family members with higher risk HFE genotypes; and because a lack of scientific evidence about HFE genotype risk does not imply an absence of risk, only a limitation of knowledge. These issues deserve attention in the general medical literature because indeterminate genotype and phenotype risk groups can be found much more frequently than groups clearly linked to increased disease risk (e.g., homozygosity). To address a gap in the literature on the extent that indeterminate results are worrisome or distressing, we collected questionnaire data in a large population-based observational study of HH screening in US and Canada. We assessed the impact of notification of HFE genotypes of indeterminate $\mathrm{HH}$ risk or elevated iron values below an alert threshold on subjects' perceived general health status, psychological well-being, health worries, and overall views on genetic testing.

\section{METHODS AND MATERIALS}

Subjects were participants of the Hemochromatosis and Iron Overload Screening (HEIRS) Study, a large observational study designed to evaluate the prevalence, risk factors, and potential clinical, personal and societal impact of $\mathrm{HH}$ and iron overload. The HEIRS study screened SF and TS levels, and the HFE C282 years and H63D alleles in a multi-ethnic sample of 101,168 adults, aged 25 years and older from five field centers in North America. Recruitment occurred in primary care clinics and offices, clinical laboratories, and health plan memberships. Study materials were available in English, Spanish, Vietnamese, and Mandarin by recruiters fluent in these languages at selected field centers. Laboratory testing was performed in a central laboratory (University of Minnesota Medical Center, Fairview, Minneapolis, MN). Participants were asked to complete a questionnaire prior to screening and after they had received their screening results. A central coordinating center (Wake Forest University, Winston-Salem, NC) conducted the data management and analysis. Details of the study design, laboratory testing, data management and analysis are described elsewhere. ${ }^{30,31}$ The study was approved by the Institutional Review Boards at each field center, the central laboratory and the coordinating center.

Results of the HEIRS screening test were mailed to all participants, and those who were homozygous for the HFE C282 years mutation or had serum transferrin saturation and ferritin values that exceeded study thresholds (TS $>50 \%$ for men or $>45 \%$ for women and SF $>300 \mu \mathrm{g} / \mathrm{L}$ for men or $>200 \mu \mathrm{g} / \mathrm{L}$ for women) were invited to attend a comprehensive clinical evaluation. The present study was limited to 1,712 participants randomly selected from the population of 40,075 HEIRS participants who did not meet criteria for the clinical evaluation but who had HFE genotypes (C282 years/+, C282 years/
H63D, H63D/H63D, or H63D/+) believed to confer a low but uncertain risk for $\mathrm{HH}$, or an "alert value" of serum transferrin saturation and/or ferritin that was above or below the middle $95 \%$ of the US population distribution as measured by the National Health and Nutrition Examination Survey III thresholds for iron overload, but did not exceed the study thresholds stated above. Additionally, a sample of 592 controls without known or suspected HFE genes and no blood iron alert level, was randomly selected among the field centers and frequency matched to the age and gender distribution of the pool of other participants not eligible for the comprehensive clinical evaluation. Thus, none of the 2,304 study participants had serum transferrin saturation and ferritin levels suggesting possible iron overload nor did they have significant genetic risk for $\mathrm{HH}$ based on C282 years homozygosity. A synopsis of HEIRS screening results letters for the indeterminate HFE risk and control groups is presented in Table 1. These study participants were sent a follow-up survey by mail that included the SF-36 general health and mental well-being scales as well as measures assessing attitudes toward genetic screening health worries, and perception of test result approximately one week after results notification. To increase survey response rates, a follow-up mailing was sent to nonresponders approximately one month after the initial mailing. Some field centers with lower response rates also contacted nonresponders by phone or in person or offered incentives for survey completion.

\section{Self-report measures}

Prior to screening, data were collected on date of birth, gender, and race/ethnicity, language preference, general mental well-being and perceived general health. For language preference, seven race/language categories were created by combining and collapsing race, ethnicity and preferred language categories: 1) English-speaking Caucasian; 2) English-speaking African-American; 3) English-speaking Asian or Pacific Islander; 4) English-speaking Hispanic; 5) Non-English-speaking Asian; 6) Non-English-speaking Hispanic; and 7) other (including English-speaking multiple races, non-Englishspeaking African-American, non-English-speaking Caucasian, and all American Indian or Alaska Native). Educational attainment was collected on the post results survey and categorized as "less than high school diploma," "high school diploma," "some university, college or vocational training," "Bachelor's degree," or "postgraduate training."

Perceived general health and general mental well-being were assessed with the SF- $36^{32}$ scales. Scale scores were calculated using published algorithms ${ }^{33}$ and change scores from baseline to follow-up were used as dependent variables. Attitude about genetic testing was assessed by level of agreement to the statement "Genetic testing to find out about disease risk is a good idea." Responses ranged from 'strongly agree' to 'strongly disagree' on a 4-point Likert scale. For analysis, this variable was dichotomized as either 'agree' or 'disagree.'

Health worry (e.g., feeling upset, sad or anxious about your test results) was assessed using nine items adapted from the Core Items of the Cancer Genetics Studies Consortium. ${ }^{34}$ An- 
Table 1

Screening result groups

\begin{tabular}{|c|c|c|c|}
\hline HFE status & Phenotypic result & Key messages & Advice (abbreviated) \\
\hline$+1+$ & $\begin{array}{l}\text { No HFE (mutations } \\
\text { No iron alert }\end{array}$ & $\begin{array}{l}\text { No genetic variations, and "your iron tests } \\
\text { are within the usual range" }\end{array}$ & $\begin{array}{l}\text { "You are welcome to share } \\
\text { this info with your MD" }\end{array}$ \\
\hline$+1+$ & $\begin{array}{l}\text { No } H F E \text { mutations. } \\
\text { Iron alert }\end{array}$ & $\begin{array}{l}\text { No genetic variations; "you do not have the } \\
\text { type of iron levels that we are } \\
\text { investigating in this study. However, the } \\
\text { result of at least one of your iron tests was } \\
\text { outside the usual range" }\end{array}$ & $\begin{array}{l}\text { "We suggest that you } \\
\text { share this info with } \\
\text { your MD" }\end{array}$ \\
\hline $\begin{array}{l}\mathrm{C} 282 \mathrm{Y} /+, \mathrm{H} 63 \mathrm{D} / \mathrm{H} 63 \mathrm{D} \\
\quad \text { or } \mathrm{C} 282 \mathrm{Y} / \mathrm{H} 63 \mathrm{D}\end{array}$ & $\begin{array}{l}\text { HFE mutations } \\
\text { No iron alert }\end{array}$ & $\begin{array}{l}\text { "Iron tests are within the usual range"; you } \\
\text { have "one or more" genetic variations } \\
\text { that "may slightly increase your risk to } \\
\text { develop iron overload in the future" }\end{array}$ & $\begin{array}{l}\text { "We encourage you to } \\
\text { 1) share" results with } \\
\text { your MD 2) "talk to a } \\
\text { genetics counselor } \\
\text { about the risk to your } \\
\text { family members" }\end{array}$ \\
\hline $\begin{array}{l}\mathrm{C} 282 \mathrm{Y} /+, \mathrm{H} 63 \mathrm{D} / \mathrm{H} 63 \mathrm{D} \\
\quad \text { or } \mathrm{C} 282 \mathrm{Y} / \mathrm{H} 63 \mathrm{D}\end{array}$ & $\begin{array}{l}\text { HFE mutation } \\
\text { Iron alert }\end{array}$ & $\begin{array}{l}\text { "You do not have the type of iron levels that } \\
\text { we are investigating in this study. However, } \\
\text { the result of at least one of your iron tests } \\
\text { was outside the usual range"; you have } \\
\text { "one or more" genetic variations that } \\
\text { "experts are not sure exactly how much } \\
\text { these changes increase your risk to develop } \\
\text { iron overload in the future" }\end{array}$ & $\begin{array}{l}\text { "We recommend that you } \\
\text { 1) "share results with } \\
\text { your MD" 2) "talk to a } \\
\text { genetics counselor } \\
\text { about the risk to your } \\
\text { family members" }\end{array}$ \\
\hline $\mathrm{H} 63 \mathrm{D} /+$ & $\begin{array}{l}\text { HFE mutation } \\
\text { No iron alert }\end{array}$ & $\begin{array}{l}\text { "Your iron tests are within the usual range"; } \\
\text { "you have a variation in one of the genes } \\
\text { that has been observed in people with iron } \\
\text { overload. However, this variation is also } \\
\text { very common in healthy people" }\end{array}$ & $\begin{array}{l}\text { "You are welcome to 1) } \\
\text { share" this info with } \\
\text { your MD"and 2) } \\
\text { "discuss with MD the } \\
\text { possibility that others in } \\
\text { your family could be at } \\
\text { risk" }\end{array}$ \\
\hline $\mathrm{H} 63 \mathrm{D} /+$ & $\begin{array}{l}\text { HFE mutation } \\
\text { Iron alert }\end{array}$ & $\begin{array}{l}\text { "You do not have the type of iron levels that } \\
\text { we are investigating in this study. However, } \\
\text { the result of at least one of your iron tests } \\
\text { was outside the usual range"; "you have a } \\
\text { variation in one of the genes that has been } \\
\text { observed in people with iron overload.... } \\
\text { It is unlikely the genetic variation identified } \\
\text { is contributing to the iron test results that } \\
\text { are described above" }\end{array}$ & $\begin{array}{l}\text { "We recommend that you } \\
\text { 1) share this information } \\
\text { with your MD" and 2) } \\
\text { "discuss with MD the } \\
\text { possibility that others in } \\
\text { your family could be at } \\
\text { risk" }\end{array}$ \\
\hline
\end{tabular}

swers ranged from 1 to 4 where $1=$ Never, $2=$ Rarely, $3=$ Sometimes, and $4=$ Often. Because the response distribution was extremely skewed, we created a dichotomous scale such that participants who answered 'Sometimes' or 'Often' to at least 1 of the 9 questions were categorized as 'worried'. Perception of genetic test result status was measured from responses to three questions asking if participants believed they had: No hemochromatosis gene abnormalities; an abnormality in just one gene; an abnormality in both genes; unsure about $\mathrm{HH}$ abnormality in 1 or 2 genes; or no $\mathrm{HH}$ abnormalities.

\section{Data analysis}

Analysis-of covariance and logistic regression models were created to test effects of the specific letter sent and the potential mediating variables on study outcomes. Participants were included in the analysis if they had a value for each variable used in the multivariable logistic regression analysis. The dependent variables included change in levels of SF-36 GH and MWB, attitudes about genetic testing, and health worries, and were adjusted for screening assessment values for: race/preferred language, age, gender, educational attainment, preferred language, SF-36 general health and mental well-being scores (follow-up - baseline value), and attitude toward genetic testing. The health worries scale was administered only after tests results were known and thus was not modeled as change from screening assessment.

\section{RESULTS}

Overall, of the 2,304 subjects, survey data were returned or collected on 1,268 participants sampled (51.5\%), 130 participants did not have information on the four outcomes and 12 additional participants were diagnosed with iron overload prior to their participation in HEIRS and were thus excluded. Predictors of not returning a survey, examined from initial screening data were male gender, nonwhite race/ethnicity, clinical site, and younger age which were statistically significant at the $P<0.05$ level. Participant characteristics not statistically associated with survey return were type of result letter received (and thus indeterminate HFE/iron overload type) and perceived health score. Table 2 pre- 
Table 2

Characteristics of the Study Sample

\begin{tabular}{|c|c|c|c|c|c|}
\hline \multirow[b]{2}{*}{ Variable } & \multirow[b]{2}{*}{ Total $^{a}$} & \multicolumn{4}{|c|}{ Letter } \\
\hline & & $\begin{array}{l}\text { Genetically normal } \\
\text { w/o iron }\end{array}$ & $\begin{array}{l}\text { Genetically normal } \\
\text { w/iron }\end{array}$ & $\begin{array}{l}\text { Genetically abnormal } \\
\text { w/o iron }\end{array}$ & $\begin{array}{c}\text { Genetically abnormal } \\
\text { w/iron }\end{array}$ \\
\hline $\mathrm{N}$ & 1,125 & 296 & 157 & 341 & 331 \\
\hline Age Mean (SD) & $49.7(13.2)$ & $48.5(12.5)$ & $48.9(14.5)$ & $51.2(13.1)$ & $49.5(13.1)$ \\
\hline \multicolumn{6}{|l|}{ Blood iron mean (SD) } \\
\hline Transferrin saturation & $28.2(14.0)$ & $27.9(8.3)$ & $22.9(16.1)$ & $29.8(8.3)$ & $29.3(19.8)$ \\
\hline Serum ferritin & $142.5(189.9)$ & $108.7(91.9)$ & $190.5(266.5)$ & $124.2(98.7)$ & $168.9(261.9)$ \\
\hline \multicolumn{6}{|l|}{ Gender N (\%) } \\
\hline Female & $795(71.2 \%)$ & $233(79.3 \%)$ & $119(77.3 \%)$ & $209(61.8 \%)$ & $234(70.9 \%)$ \\
\hline Male & $321(28.8 \%)$ & $61(20.7 \%)$ & $35(22.7 \%)$ & $129(38.2 \%)$ & $96(29.1 \%)$ \\
\hline \multicolumn{6}{|l|}{ Race N (\%) } \\
\hline Non-hispanic white & $708(62.9 \%)$ & $138(46.6 \%)$ & $73(46.5 \%)$ & $244(71.6 \%)$ & $253(76.4 \%)$ \\
\hline Black & $152(13.5 \%)$ & $58(19.6 \%)$ & $34(21.7 \%)$ & $39(11.4 \%)$ & $21(6.3 \%)$ \\
\hline Hispanic/English-speaking & $30(2.7 \%)$ & $4(1.4 \%)$ & $6(3.8 \%)$ & $11(3.2 \%)$ & $9(2.7 \%)$ \\
\hline Hispanic/non-English-speaking & $85(7.6 \%)$ & $24(8.1 \%)$ & $11(7.0 \%)$ & $24(7.0 \%)$ & $26(7.9 \%)$ \\
\hline API/English-speaking & $62(5.5 \%)$ & $36(12.2 \%)$ & $18(11.5 \%)$ & $3(0.9 \%)$ & $5(1.5 \%)$ \\
\hline API/non-English-speaking & $38(3.4 \%)$ & $21(7.1 \%)$ & $5(3.2 \%)$ & $6(1.8 \%)$ & $6(1.8 \%)$ \\
\hline Other/Unknown & $50(4.4 \%)$ & $15(5.1 \%)$ & $10(6.4 \%)$ & $14(4.1 \%)$ & $11(3.3 \%)$ \\
\hline \multicolumn{6}{|l|}{ Education N (\%) } \\
\hline$<\mathrm{HS}$ & $116(10.4 \%)$ & $31(10.5 \%)$ & $37(17.4 \%)$ & $22(6.5 \%)$ & $36(11.0 \%)$ \\
\hline HS graduate & $221(19.8 \%)$ & $64(21.7 \%)$ & $33(21.3 \%)$ & $67(19.7 \%)$ & $57(17.4 \%)$ \\
\hline Some college & $389(34.8 \%)$ & $96(32.5 \%)$ & $60(38.7 \%)$ & $114(33.5 \%)$ & $119(36.3 \%)$ \\
\hline Bachelor's degree & $169(15.1 \%)$ & $49(16.6 \%)$ & $17(11.0 \%)$ & $59(17.4 \%)$ & $44(13.4 \%)$ \\
\hline Post-graduate training & $223(20.0 \%)$ & $55(18.6 \%)$ & $18(11.6 \%)$ & $78(22.9 \%)$ & $72(22.0 \%)$ \\
\hline \multicolumn{6}{|l|}{ Health status } \\
\hline General health mean (SD) & $64.3(22.8)$ & $65.7(21.1)$ & $58.9(24.3)$ & $66.3(22.3)$ & $63.7(23.8)$ \\
\hline Mental well-being mean (SD) & $80.8(16.7)$ & $81.5(16.3)$ & $80.8(16.4)$ & $81.9(17.0)$ & $79.0(16.8)$ \\
\hline $\begin{array}{l}\text { Attitude on genetic testing } \\
\text { agree or strongly agree } \mathrm{N}(\%)\end{array}$ & $793(70.5 \%)$ & $204(68.9 \%)$ & $107(68.2 \%)$ & $246(72.1 \%)$ & $236(71.3 \%)$ \\
\hline
\end{tabular}

${ }^{a}$ Number of HEIRS participants without C282Y homozygosity and without significantly elevated TS/TF levels.

sents the demographic characteristics of study participants. Subjects had a mean age of $50.3( \pm 31.2)$ years and were predominately female (73\%). Approximately $61 \%$ self-identified as nonHispanic White, $14 \%$ as Black, nearly $11 \%$ as Hispanic $(75.4 \%$ non-English-speaking), and nearly $10 \%$ as Asian/Pacific Islander ( $40.7 \%$ of these were non-English-speaking). Most (89\%) reported completing at least high school, and approximately $70 \%$ completed some college. At the time of the follow-up survey, the mean SF-36 general health score and mental well-being scale scores were 64.3 and 80.8, respectively, out of a possible 100 (perfect health). Approximately $70 \%$ of subjects agreed that "genetic testing to find out about disease risk is a good idea."

Table 3 shows responses for the mediating variable of the participant's perception of whether or not he/she had hemo- chromatosis. Approximately $92 \%$ of respondents who received a letter indicating that they had no abnormal test results ('normals') believed that they were free of hemochromatosis. In contrast, only $63 \%$ of those who were told they had both an HFE gene abnormality and iron "alert value" believed they did not have hemochromatosis. Similarly, uncertainty about having hemochromatosis rose from $5.4 \%$ among those with normal results to $19.5 \%$ in those with both gene and iron abnormalities.

Adjusting for model covariates of age, race, gender, educational attainment and baseline values of the relevant outcomes, analysis of variance and logistic regression (data not shown) showed that the screening result letter group was not associated with perceived general health $(P=0.74)$ or attitudes 
Table 3

Perception of having hemochromatosis score by screening results letter: Percent response distribution

\begin{tabular}{ccccc}
\hline & \multicolumn{4}{c}{ Hemochromatosis $^{a}$ perception } \\
\cline { 2 - 5 } Letter & $\mathrm{N}$ & 0 & 1 & 2 \\
\hline $\begin{array}{c}\text { HFE genes normal } \\
\text { without iron alert }\end{array}$ & 289 & 93.4 & 4.5 & 2.1 \\
$\begin{array}{c}\text { HFE genes normal } \\
\text { with iron alert }\end{array}$ & 150 & 74.0 & 18.0 & 8.0 \\
$\begin{array}{c}\text { HFE genes abnormal } \\
\text { without iron alert }\end{array}$ & 321 & 75.1 & 15.3 & 9.7 \\
$\begin{array}{c}\text { Genetically abnormal } \\
\text { with iron alert }\end{array}$ & 316 & 64.2 & 18.7 & 17.1 \\
\hline
\end{tabular}

${ }^{a}$ Hemochromatosis belief: 0 = I do not have hemochromatosis; 1 = I am not sure if I have it; 2 = I have hemochromatosis.

about genetic testing $(P=0.38)$ and was statistically associated with health worry $(P<0.001)$ with the percentage of persons classified as "worried" ranging from $22 \%$ of normal controls to $40 \%$ of participants with HFE mutation(s) and an "alert value."

Table 4 presents the final analysis of variance model and logistic regression (adjusting for age, race/ethnicity, education, initial screen value of the outcome variables) for mean change in SF-36 general health and mental well-being scales and attitude about genetic testing. After considering mediators of hemochromatosis perception and extent of HFE gene abnormality (e.g., no HFE mutation; "low-risk HFE mutation group"; H63D carrier), the results letter group did not significantly predict changes in any of the outcome variables from prescreening to postresult. However, belief by participants that they had HH or had any HFE mutation, was associated with poorer outcomes in general health and mental well-being compared to those who perceived no abnormality. Participants' belief that they had any HFE mutation was also associated with attitudes about genetic testing such that those who were unsure if they had $\mathrm{HH}$ were less likely to view genetic testing positively than those who erroneously concluded they had $\mathrm{HH}$ ( $52 \%$ vs. $80 \%$ and $73 \%$ for participants who are sure that they do or do not have $\mathrm{HH}$, respectively).

Table 4 also presents the results for self-reported health worry self-reported after receiving screening results. As with the other outcomes, belief that one had HH, or had any HFE mutation was significantly associated with increasing level of health worry, while screening results letter group was not associated with belief score.

\section{DISCUSSION}

In this large multi-site study of $\mathrm{HH}$ screening and detection, participants with low or indeterminate risk HFE genotypes and/or iron "alert values" had reduced general mental wellbeing and increased health worry relative to controls with normal iron levels and no HFE mutations. Thus, our findings contribute to the literature on the impact of genetic screening on psychological well-being of patients with no prior knowledge

Table 4

Change in well-being and attitudes about genetic testing during the pre- and post-screening period, and level of health worries

\begin{tabular}{|c|c|c|c|c|c|c|c|c|}
\hline \multirow[b]{2}{*}{ Characteristic } & \multicolumn{2}{|c|}{$\begin{array}{l}\text { General } \\
\text { Health }^{a}\end{array}$} & \multicolumn{2}{|c|}{$\begin{array}{l}\text { Psychological } \\
\text { Well-being }^{a}\end{array}$} & \multicolumn{2}{|c|}{$\begin{array}{l}\text { Genetic Test } \\
\text { Attitude }^{b}\end{array}$} & \multicolumn{2}{|c|}{$\begin{array}{l}\text { Health } \\
\text { Worry }^{c}\end{array}$} \\
\hline & (PR-IS) & $P$-value & (PR-IS) & $P$-value & \% Agree & $P$-value & \%Worried & $P$-value \\
\hline Letter group & & 0.597 & & 0.900 & & 0.564 & & 0.154 \\
\hline wt/wt without iron & -7.73 & & 1.81 & & 69.3 & & 21.1 & \\
\hline wt/wt with iron & -8.41 & & 3.45 & & 68.8 & & 31.7 & \\
\hline HFE mutation without iron & -6.23 & & 2.34 & & 72.2 & & 34.2 & \\
\hline HFE mutation with iron & -6.38 & & 1.31 & & 71.3 & & 40.4 & \\
\hline Perceived hemo & & 0.029 & & 0.016 & & 0.001 & & 0.001 \\
\hline $0=$ no & -4.93 & & 4.30 & & 72.7 & & 26.8 & \\
\hline $1=$ not sure & -7.04 & & 2.81 & & 52.3 & & 45.3 & \\
\hline $2=$ yes & -9.59 & & -0.43 & & 79.8 & & 57.3 & \\
\hline Perceived gene & & 0.426 & & 0.082 & & 0.001 & & $<0.001$ \\
\hline $0=$ no gene abnormality & -5.96 & & 3.86 & & 71.8 & & 21.8 & \\
\hline $1=$ uncertain & -8.31 & & 1.42 & & 57.9 & & 42.2 & \\
\hline $2=$ one gene abnormality & -7.62 & & 3.97 & & 81.7 & & 37.9 & \\
\hline $3=$ two gene abnormalities & -6.87 & & -0.34 & & 64.7 & & 66.0 & \\
\hline
\end{tabular}

\footnotetext{
${ }^{a}$ Linear regression, post-screening result (PR) value adjusted for age, race, gender, education and prescreening (IS) value of dependent variable.

${ }^{b}$ Logistic Regression, PR value adjusted for age race, gender, education, and IS value of dependent variable.

${ }^{c}$ Logistic Regression adjusted for age, race, gender, education, and IS value of general health.
} 
of possible risk by focusing on those with low or indeterminate-risk. Effects of $\mathrm{HH}$ screening on well-being and worry in this risk group appear to be mediated by the extent that the participant believed their test results indicated they had $\mathrm{HH}$ or iron overload. Letter group, per se, was not associated with adverse well-being or worry. The overall decline in SF-36 general health and mental well-being scores from initial screening (baseline) to postresults follow-up was relatively modest, approaching a one-half standard deviation threshold for a minimal important difference held by some. ${ }^{35}$ Approximately twice as many participants who perceived presence of hemochromatosis reported health worries than those who concluded that they did not have this disorder ( 26.8 vs. $57.3 \%$ ). The effect on health worries was most closely associated with the participants' belief about the number of HFE mutations detected. The implication of these findings is that, when screening results are vague or indeterminate regarding risk of disease, people may conclude that they have an abnormality that threatens their health and, as a result, feel less well and worry more. As persons with such results may be viewed as not belonging to a clearly defined risk results group they might not be offered counseling. It is not known whether provision of genetic counseling would have alleviated this distress. In HEIRS, in the absence of knowledge about the impact of screening on wellbeing, none of the participants with detected abnormal HFE genotypes were provided follow-up medical evaluation or face-to-face genetic counseling. Numerically, some 23,695 HEIRS participants were discovered to have combinations of HFE alleles associated with indeterminate risk, or 10 times more likely than finding cases with HFE alleles viewed as clearly high-risk in this population. The requirement of genetic counseling would be a large undertaking and must be carefully weighed in study designs in the decision of whether to inform patients of indeterminate risk.

Many previous screening studies for iron overload have only notified affected individuals, thereby removing the problem of communicating uncertain risk status. Conventionally, patients aren't informed of trivial results because these results can cause only negative effects, such as stigmatization and anxiety, as mentioned above, without producing the possible gains that can result from treatment. ${ }^{36}$ This conventional approach recently, however, has been challenged as paternalisitic, and may introduce other problems $s^{37,38}$ such as withholding information pertinent to participants and families that in the future may be more clearly understood and acted upon to promote health. Some persons may want this knowledge even though there are no benefits presently available, or even if they know, perhaps as a result of researchers having informed them, that being informed may do harm. The ethical argument in favor of disclosing such results even when they risk harm is respect for patient autonomy. For participants who want to be informed of indeterminate results, it may be that, as with nontrivial risks, prior discussion of both the possible (nontrivial or trivial) findings and how persons could be prone to reacting in either case with alarm to this finding could reduce these risks. In this regard, however, there are sparse data in the literature whether genetic counseling can alleviate stress in such situations. Studies have shown marked anticipatory anxiety among those awaiting test results for various conditions or disease predispositions, ${ }^{39-43}$ though fewer have found evidence of significant psychological symptoms or emotional upset after testing, even for those found to be carriers. ${ }^{44,45-48}$ To date, most of the literature on pre- and post-genetic testing-related distress had focused either on those who knew of increased risk (e.g., for hereditary cancers or Huntington disease) prior to testing ${ }^{49}$ or on those found to have possibly increased fetal risk during pregnancy. ${ }^{50}$ Given that in the future, population screening for many late-onset disorders may reveal more genotypes with low or unclear risk than those clearly associated with disease, it is important to understand how people perceive and react to this type of result.

Our findings indicate that more research is needed on how participants perceive their results when screening for a variably expressed adult-onset genetic disease reveals mutations that may or may not confer a disease risk, and whether potential adverse effects of such results on perceived well-being and on health worries are transient or persistent. Informed consent documents for many genetic tests have specifically addressed the possibility of getting a result with unclear clinical significance; either because a particular mutation has not been reported before (as in BRCA1 or BRCA2) or because there is inadequate information about genotype/phenotype correlations for specific alleles or allele combinations (as in CFTR). Some consent documents also point out that there may be insufficient evidence to make clear recommendations about surveillance or prevention strategies if mutation(s) are found, or raise the possibility that testing could cause psychological distress or health worry. Finally, studies are needed to determine whether patients who desire to be informed of trivial risks, and are so informed have any risk for subsequent emotional harm or have enhanced relationships with the researcher or health care provider.

Although HEIRS provided a rich source of data to conduct this study, some limitations should be noted. First, with a survey response rate of $51 \%$ there is a possibility of response bias and that the actual proportion of HEIRS participants with "indeterminate" results who experienced a decline in well-being or health worry would differ from our study sample. This could occur if the majority of nonrespondents were either psychologically healthier or sicker than those who did respond. Another limitation is that our measures of well-being were necessarily brief and did not include specific measures of psychological distress, such as anxiety or life outlook that might have been affected more or less than measures of general health. Future studies might seek to better quantify if and how health worries affect daily life to better define the full impact that screening results may have on the participant. Lastly, we do not know if the changes we observed were transient or longer lasting. We will be assessing this, as well as the relationship between results and subsequent health behavior and attitudes about genetic screening, with data collected from a oneyear follow-up survey. 


\section{References}

1. Guttmacher AE Collins FS. Welcome to the genomic era. N Engl J Med 2003;349: 996-8.

2. Collins FS. A brief primer on genetic testing. Paper presented World Economic Forum, Jan 24. 2003 Porto Alegre Brazil,www.http//nhgri.nih.gov/10506784 accessed January 2005.

3. Barton JC, Acton RT. Population screening for hemochromatosis: has the time finally come? Curr Gastroenterol Rep 2000;2:18-26.

4. Motulsky AG, Beutler E. Population screening in hereditary hemochromatosis. Annu Rev Public Health 2000;21:65-79.

5. Dubois S, Kowdley KV. The importance of screening for hemochromatosis. Arch Intern Med 2003;163:2424-2426.

6. Feder JN, Gnirke A, Thomas W, Tsuchihashi Z, et al. A novel MHC class I-like gene is mutated in patients with hereditary haemochromatosis. Nat Genet 1996;13:399408.

7. Acton RT, Barton JC. Hereditary Hemochromatosis. In: Encyclopedia of Medical Genomics and Proteomics, Fuchs J, Podda M. (Editors). Marcel Dekker, Inc. New York, 2004.

8. Adams PC, Reboussin DM, Barton JC, McLaren CE, et al. Hemochromatosis and Iron- Overload Screening in a Racially Diverse Population. N Engl J Med 2005;352: 1769-1778.

9. Adams $\mathrm{P}$, Acton R, Walker A. A primer for predicting risk of disease in HFE-linked hemochromatosis. Genetic Testing 2001;5:311-316.

10. Adams PC, Reboussin DM, Barton JC, McLaren CE, et al. Hemochromatosis and Iron-Overload Screening in a Racially Diverse Population. N Engl J Med 2005;352: 1769-1778.

11. Asberg A, Hveem K, Thorstensen K, Ellekjaer E, et al. Screening for hemochromatosis - high prevalence and low morbidity in an unselected population of 65,238 persons. Scand J Gastroenterol 2001;36:1108-1115.

12. Adams PC, Passmore L, Chakrabarti S, Reboussin D, et al. Liver diseases in the Hemochromatosis and Iron Overload Screening Study. Clin Gastroenterol Hepatol 2006;4:918-923.

13. Adams PC, Deugnier Y, Moirand R, Brissot P. The relationship between iron overload, clinical symptoms and age in 410 patients with genetic hemochromatosis. Hepatology 1997;25:162-166.

14. Powell L, Dixon J, Ramm G, Purdie D, et al. Screening for hemochromatosis in asymptomatic subjects with or without a family history. Arch Int Med 2006;166:294301

15. Adams PC, Speechley M, Kertesz AE. Long-term survival analysis in hereditary hemochromatosis. Gastroenterology 1991;101:368-372.

16. Niederau C, Fischer R, Purschel A, Stremmel W, et al. Long-term survival in patients with hereditary hemochromatosis. Gastroenterology 1996;110:1107-1119.

17. Barton JC, McDonnell SM, Adams PC, Brissot P, et al. Management of hemochromatosis. Hemochromatosis Management Working Group. Ann Intern Med 1998; 129:932-939.

18. Niederau C, Fischer R, Purschel A, Stremmel W, et al. Long-term survival in patients with hereditary hemochromatosis. Gastroenterology 1996;110:1107-1119.

19. Anderson RT, Press N, Tucker DC, Snively BM, et al. Patient acceptability of genotypic testing for hemochromatosis in primary care. Gen Med 2005;7:557-563.

20. Patch C, Roderick P, Rosenberg W. Comparison of genotypic and phenotypic strategies for population screening in hemochromatosis: Assessment of anxiety, depression, and perception of health. Genet Med 2005;7:550-556.

21. Adams PC. Screening for haemochromatosis—producing or preventing illness? Lancet 2005;366:269-271.

22. Hall MA, McEwen JE, Barton JC, Walker AP, et al. Concerns in a primary care population about genetic discrimination by insurers. Gen Med 2005;7:311-316.

23. Boyle P. Introduction to Genetic Grammar: Health, Illness, and the Human Genome Project. Hastings Center Report 1992;22:S1.

24. Wertz DC, Fletcher JC, eds. Ethics and Hum Genet: A Cross-cultural Perspective. New York: Springer-Verlag, p. 5361989.

25. Broadstock M, Michie S, Marteau T. Psychological consequences of predictive genetic testing: a systematic review. Eur J Hum Genet 2000;8:731-738.

26. Bish A, Sutton S, Jacobs C, Levine S, et al. No news is (not necessarily) good news: impact of preliminary results for BRCA1 mutation searches. Genet Med 2002;4:353358
27. Power TE, Adams PC. Psychosocial impact of C282Y mutation testing for hemochromatosis. Genet Test. 2001;5:107-110.

28. McLaren CE, Barton JC, Adams PC, Harris EL, et al. Hemochromatosis and iron overload screening (HEIRS) study design for an evaluation of 100,000 primary carebased adults. Am J Med Sci 2003;325:53-62.

29. Ware J, Snow K, Kosinski M, Gandek B. SF-36 Health Survey: Manual and Interpretation Guide. Boston, MA: The Health Institute, New England Medical Center, 1993.

30. Cancer Epidemiology Biomarkers and Prevention. Special Issue: Psychosocial Aspect of Cancer Genetic Testing. Findings from the Cancer Genetics Studies Consortium, Vernon SW, Bowen D, Patenaude AF, (Editors). 1999.

31. Norman GR, Sloan JA, Wyrwich KW. Interpretation of changes in health-related quality of life: the remarkable universality of half a standard deviation. Med Care 2003;41:582-592.

32. Horowitz MJ, Field NP, Zanko A, Donnelly EF, et al. Psychological impact of news of genetic risk for Huntington disease. Am J Med Genet 2001;103:88-92.

33. Coyne JC, Kruus L, Racioppo M, Calzone KA, et al. What do ratings of cancerspecific distress mean among women with high risk of breast and ovarian cancer? Am J Med Genet 2003;116A:222-228.

34. Bonadona V, Saltel P, Desseigne F, et al. Cancer patients who experienced diagnostic genetic testing for cancer susceptibility: reactions and behavior after the disclosure of a positive test result. Cancer Epidemiol Biomarkers Prev 2002;11:97-104.

35. Dorval M, Patenaude AF, Schneider KA, Kieffer SA, et al. Anticipated versus actual emotional reactions to disclosure of results of genetic tests for cancer susceptibility: Findings from p53 and BRCA1 testing programs. J Clin Oncol 2000;18:2135-2142.

36. Lodder L, Frets PG, Trijsburg RW, Meijers-Heijboer EJ, et al. Psychological impact of receiving a BRCA1/BRCA2 test result. Am J Med Gen 2001;98:15-24.

37. Decruyenaere M, Evers-Kiebooms G, Cloostermans T, Boogaerts A, et al. Psychological distress in the 5-year period after predictive testing for Huntington's Disease. Eur J Hum Genet 2003;11:30-38.

38. Gordon C, Walpole I, Zubrick SR, Bower C. Population Screening for cystic fibrosis: knowledge and emotional consequences 18 months later. Am J Med Genet 2003;120: A199-A208.

39. van Maarle MC, Stouthard ME, Marang-van de Mheen PJ, Klazinga NS, et al. How disturbing is it to be approached for a genetic cascade screening programme for familial hypercholesterolaemia? Psychological impact and screenees' views. Community Genet 2002;4:244-252.

40. Lerman C, Narod S, Schulman K, Hughes C, et al. BRCA1 testing in families with hereditary breast-ovarian cancer. JAMA 1996;275:1885-1892.

41. Tercyak KP, Johnson SB, Roberts SF, Cruz AC. Psychological response to prenatal genetic counseling and amniocentesis. Patient Education and Counseling 2001;43:73.

42. Parker LS. Rethinking Respect for Persons Enrolled in Research. American Society for Bioethics and Humanities Exchange 2006;9:1-6.

43. Shalowitz DI, Miller FG. Disclosing Individual Results of Clinical Research. JAMA 2005;294:737-740.

44. In Reply: Implications of Disclosing Individual Results of Clinical Research. JAMA 2006;295:37-38.

45. Keller M, Jost R, Haunstetter CM, Kienle P, Knaebel HP, Gebert J, Sutter C, KnebelDoeberitz M, Cremer F, Mazitschek U. Comprehensive genetic counseling for families at risk for HNPCC: impact on distress and perceptions. Genet Test Winter 2002;6:291-302.

46. Decruyenaere M, Evers-Kiebooms G, Cloostermans T, Boogaerts A, et al. Psychological distress in the 5-year period after predictive testing for Huntington's disease. Eur J Hum Genet 2003 Jan;11:30-8.

47. Claes E, Denayer L, Evers-Kiebooms G, Boogaerts A, et al. Predictive testing for hereditary nonpolyposis colorectal cancer: subjective perception regarding colorectal and endometrial cancer, distress, and health-related behavior at one year posttest. Genet Test Spring 2005;9:54-65.

48. Hamann HA, Somers TJ, Smith AW, Inslicht SS, et al. Posttraumatic stress associated with cancer history and BRACA1/2 genetic testing. Psychosom Med 2005;67: 766-72.

49. Meiser B, Dunn S. Psychological impact of genetic testing for Huntington's disease: an update of literature. J Neurol Neurosurg 2005;69:574-8.

50. Tereyak KP, Johnson SB, Roberts SF, Cruz AC. Psychological response to prenatal genetic counseling and amniocentesis. Patient Educ Couns 2001;43:73-84. 